Concepciones y creencias docentes sobre la democracia en el colegio

Teachers' conceptions and beliefs about democracy in schools

\title{
Lucía Ginocchio
}

Pontificia Universidad Católica del Perú

lucia.ginocchio@pucp.pe

Susana Frisancho

Pontificia Universidad Católica del Perú sfrisan@pucp.edu.pe

María Isabel La Rosa

Pontificia Universidad Católica del Perú mlarosa@pucp.edu.pe

Recibido: 09-5-2015

Aprobado: 23-6-2015 


\title{
Resumen
}

El proceso de construcción de la democracia en el colegio tiene como actor principal al docente, cuyas concepciones y creencias influirán en su práctica pedagógica. Por este motivo, el presente estudio tuvo como propósito explorar las creencias de los docentes sobre la democracia en un colegio en la ciudad de Lima, Perú. Se entrevistó a ocho profesores de una institución educativa pública secundaria. Los resultados mostraron que los docentes no reconocen la construcción de una sociedad democrática como un fin de la educación, sino que perciben que su objetivo principal es formar emprendedores preparados para el mundo laboral. La mayoría concibe la democracia principalmente como un sistema de gobierno y no como forma de vida. A nivel escolar, la democracia se entiende principalmente como participación en programas escolares o acciones centradas en el docente. Los profesores consideran que las familias no contribuyen con la formación de los estudiantes y que el colegio no puede hacer nada por los estudiantes con familias problemáticas. Además, sus creencias sobre su rol como docentes los distancian de posturas democráticas, así como sobre la disciplina. Estos resultados se discuten enfatizando en el rol de la escuela para la formación de una ciudadanía democrática.

Palabras clave: creencias docentes, democracia, colegio democrático, formación ciudadana, educación secundaria

\begin{abstract}
Building democracy in schools is a process in which teachers are fundamental actors. This is because their conceptions and beliefs significantly influence their pedagogical practice. Thus, this study intends to explore teachers' beliefs about democracy and its role within the educational system. Eight public secondary school teachers where intereviewed for the study. Results show that teachers do not recognize building a democratic society as one of the aims of education. Instead, they perceive entrepreneurship and developing working skills as its principal aims. Most teachers understand democracy only as a government system and not as a way of living. Democracy in the school is understood mainly as involvement in school programs or teacher centered actions. Moreover, teachers consider families cannot contribute to students' education and believe that school cannot do anything to help students with dysfunctional families. Additionally, they hold beliefs about their role as teachers that distance them from democratic stances and from democratic discipline. Results are discussed focusing on the school role for democratic education.
\end{abstract}

Keywords: teachers' beliefs, democracy, democratic school, citizenship education, secondary education 


\section{Concepciones y creencias docentes sobre la democracia en el colegio}

\section{Introducción}

El proceso de democratización del colegio necesariamente involucra a los docentes, pues son una parte esencial del proceso educativo y, desde una mirada constructivista, funcionan como mediadores del aprendizaje. En el campo de la educación ciudadana, esta concepción del profesor refuerza su lugar como facilitador de una cultura democrática que fomenta el desarrollo del estudiante y su formación como ciudadano. Sin embargo, el papel del docente como formador de ciudadanos no está exento de dificultades. Las barreras de los docentes para ser agentes y facilitadores de una cultura democrática en el colegio se evidencian en prácticas poco democráticas que suelen ser frecuentes en nuestro contexto, las que se ven ejemplificadas en la violencia que ocurre con regularidad en las instituciones educativas. Dicha violencia se sostiene en un paradigma disciplinar autoritario y rígido (Benavides, 1997; Callirgos, 1995; Espinoza, 1993; Rojas, 2011; Trinidad, 1999; Zeballos, 2012) y en las relaciones verticales entre los diversos agentes educativos (Evans, 2004; Oliart, 1996), lo que genera un clima escolar poco integrador y perpetúa un sistema autoritario. Se vuelve evidente, entonces, que existe una brecha entre los fines educativos y aquello que se espera del actuar docente, por un lado, y las prácticas que ocurren en lo cotidiano, por otro. Como afirma Leal, «los profesores tienden a identificarse con los modelos y prácticas tradicionales, lo que generaría un efecto de continuidad más que de cambios» $(2005$, p. 1). Además, se sienten poco capacitados y con dificultades para promover una cultura democrática en la escuela (Apaza, 2009).

Así, vemos que los docentes poseen una estructura de creencias que juega un papel relevante en su práctica pedagógica. Cabe anotar que las creencias son juicios o evaluaciones que son aceptadas como una verdad por el individuo que las sostiene. De esta manera, quedan impregnadas de compromisos afectivos y, consecuentemente, guían el pensamiento y la acción, en la medida que aquello que los profesores hacen o pueden hacer está estrechamente vinculado con sus creencias (Catalán, 2011). Las creencias cooperan con la búsqueda de sentido del mundo por parte del individuo, e influyen en la manera en que la información es percibida y si esta es aceptada o no. Además, median la información que es almacenada en la memoria con sus juicios y evaluaciones, y sirven como un marco para comprender el contexto (Borg, 2001). En ese sentido, las creencias son consideradas filtros de información que tienen incidencia en el almacenamiento, recuperación y utilización del conocimiento y, a su vez, pueden reemplazarlo (Catalán, 2011). Estas no pueden ser medidas u observadas directamente, sino que deben ser necesariamente inferidas del discurso, puesto que se encuentran implícitas en las afirmaciones de los individuos (Pajares, 1992). 
Una diferencia importante entre creencias y concepciones es que las primeras tienen un componente afectivo más intenso y predominante que las segundas. Estas últimas son más abarcadoras, tienen un menor nivel de subjetividad, y -según varios autores (ver Ponte, 1999)- pueden incluir a las creencias, pero también a los significados, conceptos, proposiciones, preferencias y gustos.

Como ya se mencionó, las concepciones y creencias juegan un papel muy importante en la enseñanza y son relevantes para el desarrollo de la práctica docente. Tomando en cuenta todo lo anterior y ante la escasez de investigaciones sobre este tema en el Perú, este estudio tuvo como propósito explorar las concepciones y creencias que tienen los docentes de una institución educativa pública de la ciudad de Lima, Perú, acerca de la democracia en el colegio.

\section{Democracia y educación}

La democracia es ampliamente reconocida como el mejor sistema político para el gobierno de un país. Esta se funda a partir de ideales como la tolerancia, la convivencia y resolución de conflictos sin violencia, la renovación gradual de la sociedad mediante el libre debate de ideas y el ideal de la fraternidad, que une a todas las personas en un destino común (Bobbio, 2001). En este sentido, la democracia se relaciona íntimamente con el respeto de los derechos humanos, la inclusión de las minorías en la toma de decisiones concertadas, el reconocimiento del otro, la legitimidad del consenso, y la autonomía de los individuos. De esta manera, significa para una sociedad un medio importante para asegurar el bienestar y las oportunidades de sus ciudadanos (Nussbaum, 2008, 2010).

La democracia suele entenderse principalmente como un sistema político de estructuración del Estado, conformado por instituciones y mecanismos legales. Sin embargo, en una concepción más amplia, es también una forma de vida en común, una cultura

en la que las personas se relacionan entre sí con el fin de construir y consolidar una convivencia humana armónica que permita el bienestar y el desarrollo pleno de todos [... que] debe, por supuesto, estar sustentada en un sistema de instituciones, mecanismos y leyes que buscan garantizar los derechos de las personas y de los pueblos (Ministerio de Educación del Perú [Minedu], 2005, p. 9).

Esta noción de convivencia democrática se funda en el consenso intercultural, es decir, en una cultura política que hace posible la deliberación pública y la acción concertada, y que reconoce las diversas identidades (Tubino, 2009), una "ciudadanía diferenciada», como la denominan Kymlicka y Norman (2002). La democracia, como sistema y como cultura, se expresa con mayor o menor intensidad en los distintos ámbitos sociales en un país. Como afirman Dibós, Frisancho y Rojo: 
hay muchos países cuyo sistema se reconoce como democrático y que, sin embargo, no despliegan la misma intensidad de democracia (sea como sistema o como cultura) en los distintos ámbitos de sus realidades sociales. Por ello, se puede afirmar que hay países con mayor o menor libertad de expresión, con mayor o menor tolerancia y reconocimiento de las diferencias, con más o con menos mecanismos reales de participación ciudadana, etc. (2004, p. 1).

Si bien un país puede estar organizado bajo un sistema político democrático, esto no garantiza que posea una cultura democrática. Del mismo modo, se puede encontrar en una sociedad ejemplos de participación y organización democrática sin que su sistema de gobierno lo sea. Si bien el fortalecimiento de una cultura democrática ayuda a consolidar el sistema democrático, lo ideal es que tanto cultura como sistema se desarrollen de manera conjunta (Dibós et. al., 2004). No obstante, «el vigor y la estabilidad de una democracia moderna no dependen solamente de la justicia de su estructura básica sino también de las cualidades y actitudes de sus ciudadanos» (Kymlicka y Norman, 2002, p. 5), entre ellas, la capacidad de los individuos de reconocerse diferentes, sin que esto signifique un impedimento para trabajar en conjunto (Touraine, 1995).

En suma, la construcción de una cultura democrática tiene por objetivo generar una sociedad más justa e inclusiva. Sociedades con mayor participación democrática poseen mejores niveles de representación política de los intereses de sus ciudadanos y, por consiguiente, procesos de desarrollo de políticas públicas más equilibrados (Carrión, Zárate y Seligson, 2012). Por el contrario, sociedades poco democráticas suelen ser excluyentes y marginan a ciertos grupos, lo cual les impide sentirse miembros plenos de una sociedad de iguales, capaces de participar y disfrutar de la vida en común (Marshall, 1992). Tampoco promueven la autonomía (Nussbaum, 2008), lo que afecta la percepción del individuo sobre sus capacidades políticas (Lassen y Serritzlew, 2011, en Carrión et ál., 2012). Se espera que, en una sociedad, la experiencia educativa de todos los individuos contribuya con el desarrollo de una cultura democrática. Por ello, a continuación, se abordará la relación entre educación y democracia.

La educación es un proceso de enorme importancia para la consolidación de las metas democráticas de una sociedad (Dewey, 2004; Freire, 2010; Giroux, 2008; Oser, Althof y Higgins-D’Alessandro, 2008; Kolhberg, 1985, en Oser et ál., 2008; Power, Higgins y Kohlberg, 1989). Esto es ampliamente reconocido en nuestro país: uno de los fines de la educación peruana es la construcción de una cultura democrática; la Ley General de Educación, en su noveno artículo, establece la democracia como un principio de la educación (Congreso de la República del Perú, 2003, inciso B).

En la educación formal, la institución escolar es un espacio de socialización fundamental (Durkheim, 1976). Allí ocurren las primeras experiencias de pertenencia a una institución con normas, reglas y prácticas de interacción que brindan oportunidades para la convivencia, la participación y la regulación de 
conflictos (Ames, 1999; Tallone, 2010), y permiten desarrollar competencias ciudadanas. $\mathrm{Al}$ respecto, algunos estudios comprueban que los individuos con mejores niveles educativos son los que suelen estar más informados, ser tolerantes, valorar instituciones democráticas y demostrar un mayor compromiso político (Hillygus, 2005 en Veramendi, 2012; Glaeser, Ponzetto y Shleifer, 2006; Schwartzman, 2008 en Veramendi, 2012).

Sin embargo, se sabe que las creencias de los profesores sobre la democracia o la ciudadanía son diversas. En algunos colegios, estas se fundan en principios democráticos explícitos y apuntan al constante ejercicio crítico y reflexivo como estrategia para la formación ciudadana, mientras que en otros los profesores tienen más bien una visión que asocia la ciudadanía fundamentalmente a los desfiles y a la celebración de actos cívicos (Guerra, 2014). La investigación ha demostrado, también, que los docentes pueden ejercer su rol pedagógico de manera no inclusiva, y contraria a los principios explícitos de respeto y no discriminación que la escuela puede tener en su concepción de ciudadanía, sin ser conscientes de los prejuicios con los cuales operan. Por ejemplo, una investigación llevada a cabo por Becerra (2011) concluye que la presencia de un sistema de creencias prejuicioso y estereotipado en un grupo de docentes chilenos sobre sus estudiantes mapuches se manifiesta en sus prácticas, que tienden a ser paternalistas y discriminadoras. Las creencias de estos docentes tuvieron consecuencias en la relación con los alumnos, una relación asimétrica en la que el docente se ubicaba por encima de los estudiantes, les daba mensajes de inferioridad y -a la vez- les asignaba una posición de desventaja y minusvalía. Así, se nota que, si bien los docentes pueden manejar conocimiento explícito que expresa el ideal o el deber ser, si sus creencias no se articulan con este conocimiento o son opuestas a él, pueden sustituirlo (Catalán, 2011). Análogamente, si bien los profesores son capaces de manejar un discurso sobre el colegio como propulsor de una cultura democrática, si sus creencias más profundas son poco democráticas, es muy probable que sus prácticas sean contrarias a los conocimientos de los que pueden dar cuenta de manera explícita.

\section{Método}

\subsection{Participantes}

Se seleccionó a 8 docentes de secundaria de una institución educativa pública del distrito de Magdalena, en la ciudad de Lima: 6 mujeres y 2 hombres de entre 40 y 59 años, con experiencia laboral de 14 a 29 años. Siete de ellos eran nombrados y uno contratado. Todos eran titulados en Educación y seis estudiaron, adicionalmente, otras carreras: Diseño Publicitario, Informática, Gastronomía, Enfermería, Turismo y Hotelería, Ingeniería Física Nuclear y Ciencias de la Comunicación. Seis de los ocho docentes participaron en cursos de actualización pedagógica, como el Plancad o el Pronafcap. El colegio en el que desempeñan su labor docente es representativo de las instituciones educativas 
públicas de la ciudad de Lima, que sí considera importante la formación en democracia en su proyecto educativo institucional y en su plan anual de trabajo. Los profesores firmaron un consentimiento informado y asumieron participar del estudio de forma voluntaria. La siguiente tabla resume las principales características de los participantes:

Tabla I. Características de los profesores participantes

\begin{tabular}{|c|c|c|c|c|c|c|c|c|}
\hline $\begin{array}{l}\stackrel{0}{0} \\
\stackrel{0}{0} \\
0 \\
0\end{array}$ & 这 & 苛 & 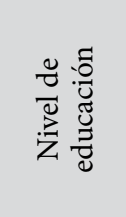 & 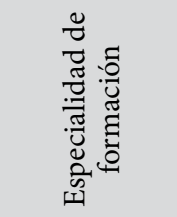 & 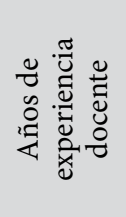 & 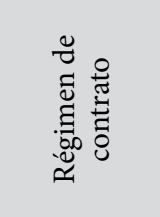 & 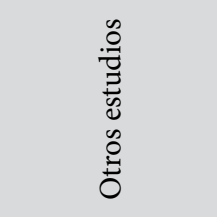 & 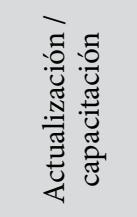 \\
\hline P1 & $\mathrm{F}$ & 45 & Magíster & $\begin{array}{l}\text { Lengua y } \\
\text { literatura }\end{array}$ & 25 & Nombrada & $\begin{array}{c}\text { Ciencias } \\
\text { de la } \\
\text { Comunicación }\end{array}$ & $\begin{array}{c}\text { Sí. } \\
\text { Pronafcap } \\
\text { en } 2008\end{array}$ \\
\hline P2 & $\mathrm{F}$ & 52 & Superior & $\begin{array}{l}\text { Educación } \\
\text { física / Ed. } \\
\text { Especial }\end{array}$ & 29 & Nombrada & No. & Sin dato \\
\hline P3 & $\mathrm{M}$ & 59 & Superior & $\begin{array}{c}\text { Matemática } \\
\text { y } \\
\text { computación }\end{array}$ & 28 & Nombrado & $\begin{array}{c}\text { Ingeniería física / } \\
\text { nuclear }\end{array}$ & $\begin{array}{c}\text { Sí. } \\
\text { Pronafcap } \\
\text { en } 2011\end{array}$ \\
\hline P4 & $\mathrm{F}$ & 56 & Magíster & $\begin{array}{c}\text { Informática } \\
y \\
\text { computación }\end{array}$ & 23 & Contratada & Enfermería & $\begin{array}{c}\text { Sí. } \\
\text { Plancad } \\
\text { en } 2004 .\end{array}$ \\
\hline P5 & $\mathrm{F}$ & 50 & Superior & $\begin{array}{l}\text { Biología y } \\
\text { química }\end{array}$ & 25 & Nombrada & $\begin{array}{c}\text { Diseño } \\
\text { publicitario }\end{array}$ & $\begin{array}{c}\text { Sí. } \\
\text { Pronafcap } \\
\text { en } 2009\end{array}$ \\
\hline P6 & $\mathrm{M}$ & 40 & Superior & $\begin{array}{c}\text { Matemática } \\
\text { y física }\end{array}$ & 15 & Nombrado & $\begin{array}{l}\text { Informática y } \\
\text { gastronomía }\end{array}$ & $\begin{array}{c}\text { Sí. } \\
\text { Plancad }\end{array}$ \\
\hline P7 & $\mathrm{F}$ & 42 & Superior & $\begin{array}{l}\text { Biología y } \\
\text { química }\end{array}$ & 14 & Nombrada & No. & $\begin{array}{c}\text { Sí. } \\
\text { Pronafcap } \\
\text { en } 2009\end{array}$ \\
\hline P8 & $\mathrm{F}$ & 57 & Superior & $\begin{array}{l}\text { Lengua y } \\
\text { literatura }\end{array}$ & 26 & Nombrada & $\begin{array}{l}\text { Turismo y } \\
\text { hotelería }\end{array}$ & No \\
\hline
\end{tabular}

Fuente: Elaboración propia

\subsection{Técnica de recolección de información}

La información se recolectó mediante entrevistas cualitativas de una duración promedio de una hora. La entrevista tuvo como objetivo identificar las concepciones y creencias de los docentes acerca del colegio democrático, y contó con las siguientes áreas: 
- Objetivos de la educación: Exploró las ideas que tienen los docentes sobre los fines de la educación y su relación con la formación de ciudadanos democráticos. Se preguntó, por ejemplo, «¿Cuál es el objetivo o fin que considera más importante conseguir en relación con sus estudiantes?» o «En otras palabras, si pudiera reducir todo a una meta o logro, ¿cuál cree usted que es la más importante de lograr con sus alumnos?».

- Concepciones sobre los reglamentos: A partir de un caso que describe una experiencia fallida de participación de estudiantes en la elaboración del reglamento escolar, se buscó recoger las opiniones de los docentes sobre la disciplina y la participación de los estudiantes en la toma de decisiones del colegio. Sobre la base de lo narrado en el caso, en esta sección se realizaron preguntas como «¿Cómo cree que debieron actuar los profesores ante el comportamiento de los alumnos el día de la consulta?», «iPor qué?», «¿Qué problemas pueden surgir si se involucra a los estudiantes en la toma de decisiones del colegio?», «¿Cuáles serían los beneficios de involucrarlos?».

- Conocimientos y valoración de la democracia: Se indagó sobre la información con la que cuenta el docente acerca de la democracia, sus características, los aspectos considerados positivos o negativos de la democracia y el valor que le asignan. Por ejemplo, en esta sección se planteó la siguiente pregunta: «Algunas personas piensan que la democracia es un logro muy importante para que se pueda gobernar un país. Sin embargo, otros piensan que lo que se necesita es un gobierno de mano dura, que tome decisiones rápidas y efectivas. ¿Con cuál de las dos posiciones está más de acuerdo? ¿Por qué no eligió la otra?». Finalmente, se pidió brindar una definición de democracia.

- Percepción sobre la democracia en el colegio: Se exploró las representaciones de los profesores sobre lo que significa la democracia en el colegio, la posibilidad de que esta se construya en dicha institución, lo factible de que se consiga este logro, la transversalidad de la democracia a lo largo de las áreas curriculares y las características de un colegio democrático. Por ejemplo, se preguntó: «En la página 10 del DCN 2009, se menciona que la educación debe «[...] contribuir a formar una sociedad democrática, solidaria, justa, inclusiva, próspera, tolerante y forjadora de una cultura de paz [...]». ¿Cree usted que un colegio puede lograr estos objetivos? ¿Por qué? ¿Cómo se consiguen estos logros?».

\subsection{Procedimiento}

Una vez diseñada, piloteada y ajustada la guía de entrevista, se estableció contacto con el colegio seleccionado y se informó sobre el estudio al director, el subdirector y luego a los docentes, quienes fueron citados para una entrevista individual dentro de la institución educativa. Las entrevistas, que se efectuaron durante la primera mitad del año 2013, fueron grabadas, transcritas y 
analizadas por 2 jueces, y la codificación del contenido se realizó con el programa Atlas-ti. Tal como es descrito por Hernández, Fernández-Collado y Baptista (2010), primero se produjo un sistema de clasificación o tipologías y, después, se realizó la presentación de temas y teorías obtenidas. Posteriormente, se recurrió a dos de los docentes participantes en el estudio para realizar una validación de la codificación. Mediante el análisis de viñetas extraídas de su propia entrevista, se llevó a cabo el proceso de validación de los códigos establecidos por la investigadora y se llegó al 75,8\% y al 88,6\% de acuerdo entre los participantes y la investigadora sobre los códigos propuestos. Finalmente, se procedió a un nuevo análisis y se afinaron algunos de los códigos propuestos inicialmente.

\subsection{Resultados}

Los resultados se presentan en tres apartados. En el primero, se describe las concepciones de los docentes sobre los fines que persigue la educación. En el segundo, se detalla las concepciones y creencias sobre la democracia. Por último, se describen las concepciones y creencias sobre la democracia en el colegio desde sus requisitos y barreras.

\section{Concepciones sobre los fines de la educación}

Con respecto a los fines que persigue la educación, las respuestas brindadas por los participantes comprenden cuatro ideas centrales: tener un futuro, dominar conocimiento específico de un área, desarrollar habilidades, y la formación integral. Siete de los ocho participantes del estudio manifestaron que tener un futuro es la principal finalidad de la educación (P2, P3, P4, P5, P6, P7 y P8). Para ellos, la idea de tener un futuro como fin de la educación implica formar emprendedores o profesionales técnicos que consigan un trabajo con el cual aseguren recursos económicos. «Tener un futuro» implica, también, conseguir estudios superiores, tener una carrera técnica, o estudiar y trabajar.

P2: [...] entonces, el objetivo de la educación peruana debe ser que el joven o la joven pueda tener un futuro [...]. Un futuro que se sientan ellos capaces de lograr un trabajo, de lograr una realización financiera, no como un banco, la finanza para ellos mismos, tener un pan de cada día.

P3: La meta es formar jóvenes preparados para el futuro [...] que tengan una profesión y que se desenvuelvan para emplearse en el algún oficio, una carrera.

P4: Bueno, los estudiantes de este colegio están preparados para un futuro y un trabajo inmediato, porque a los estos alumnos su preparación 
es para que tengan un trabajo tecnológico e inmediato. Esa es la visión del colegio. [...] el colegio está preparando a niños y adolescentes, este, para un futuro inmediato del trabajo, los preparamos en marketing empresarial, ¿no? y en manualidades.

P6: [...] que sean emprendedores en el sentido que sean más adelante empresarios [...]; estamos buscando a que ellos puedan salir, cómo se llama, de un problema si no tienen un trabajo, si no consiguen un lugar; aquí en esta institución se les enseña a los talleres y les hace ver que pueden hacer, pueden depender de sí mismos ¿no?

Del total de docentes que afirmaron que tener un futuro es el objetivo central de la educación, tres argumentaron que su finalidad también comprende formar individuos con valores, con habilidades sociales o que sean mejores personas y ciudadanos (P4, P5, P8). Sin embargo, la formación de valores, habilidades sociales y ciudadanía para estos docentes son solo medios para conseguir tener un futuro. Por ejemplo, la responsabilidad es vista como un valor necesario para poder sacar adelante una empresa y, por eso, formar a los estudiantes para que sean responsables es una meta educativa.

P4: Los valores, obviamente, los valores [...] la honestidad [...] En todo trabajo, buscan que el individuo sea honesto; si un individuo es honesto, va a tener las puertas de los trabajos abiertos, porque un empleador te pone pruebas, miles de pruebas.

P5: [...] tienen que tener valores. Eso es lo que es más importante ahora, porque los chicos, ¿de qué te vale que tengan solo conocimientos? Si no tiene valores y ellos deben salir, ser responsables, porque para hacer una empresa, lo que sea, también tienes que ser responsable, sino ¿cómo vas a cumplir?

Asimismo, los docentes plantearon como fin de la educación brindar a los estudiantes conocimientos correspondientes a cada área curricular (P1, P2, P3, P6 y P7).

P1: [...] en realidad, cada área tiene su propósito pedagógico. En el caso de nosotros, de comunicación, el propósito es desarrollar habilidades comunicativas en los chicos, tanto orales como escritas, e incluso ahora las audiovisuales, que son las que comúnmente ellos trabajan, en términos de audiovisión.

P3: Es que dominen las matemáticas, que es la madre de todas las ciencias.

P7: Lo relacionado a las capacidades de área que viene en el curso de CTA que son las exigencias que pone el Ministerio de Educación que hay que cumplir. 
Adicionalmente, dos participantes plantearon como fin de la educación formar estudiantes críticos que desarrollen las habilidades de resolución de problemas y toma de decisiones:

P1: [...] que los chicos sean críticos ante una problemática. Que ellos afronten ese problema y aprendan a tomar una solución, pero desde su óptica, desde su punto de vista. Entonces, si los maestros le damos herramientas para que ellos sean críticos, para que tomen decisiones frente a una problemática y para que den la respuesta a esa problemática, desde su ámbito y en cualquier ámbito fuera del colegio, yo creo que es un paso adelante que la educación al menos en esta institución puede dar.

P7: Muy aparte de los conocimientos, si no tienen las habilidades de solucionar problemas, tomar buenas decisiones, es muy difícil que puedan tener este, se podría decir, buenos resultados en su vida, en su vida personal, académica.

Por último, un docente añadió que la finalidad de la educación es la formación integral, como se expresa en la siguiente viñeta:

P7: [...] formar al ser humano en forma integral, tanto en conocimientos, en valores en actitudes [...] Haber adquirido ciertas capacidades, ciertas destrezas que les sirva en su vida diaria, que le permita desenvolverse en su entorno, que puedan enfrentar situaciones que se le presenten. [...], el dominio de temas básicos, por ejemplo ,que le corresponde para su edad, para su grado; en cuanto a actitudes, también, [...] por ejemplo, la actitud del emprendimiento, la actitud de tener iniciativa, de solucionar problemas, de tomar decisiones, y aparte, valores necesarios, respeto, responsabilidad.

Como se observa, los docentes asociaron los fines educativos con la vinculación entre la vida del estudiante y el mundo del trabajo («tener un futuro»), así como el desarrollo de capacidades y habilidades, conocimientos y sentido crítico. Sin embargo, no se relacionaron estas ideas con el ejercicio de la ciudadanía. Incluso, al mencionar que la formación integral es el objetivo de la educación, el docente hace énfasis en que esta permite la «actitud del emprendimiento, la actitud de tener iniciativa, de solucionar problemas, de tomar decisiones, y aparte, valores necesarios, respeto, responsabilidad» (P7, el énfasis es añadido por las autoras), sin evidenciar explícitamente su vínculo con la formación de ciudadanos democráticos.

Esta desvinculación entre la formación de una sociedad democrática y los objetivos educativos evidencia una orientación a metas de corto plazo y de naturaleza fundamentalmente individual. En otras palabras, las concepciones 
de los docentes sobre los fines que persigue la educación muestran desconocimiento y poca claridad sobre los fines democráticos que se espera lograr desde el ámbito educativo.

Teniendo en cuenta que los profesores son reconocidos como agentes fundamentales en el proceso educativo (Congreso de la República del Perú, 2003, artículo 56), y son agentes de socialización y mediadores del aprendizaje de sus estudiantes (Wertsch, 2007), una reflexión que se desprende de lo encontrado es la importancia del trabajo reflexivo con ellos para el reconocimiento de la formación de una sociedad democrática como un fin de la educación.

\section{Concepciones y creencias sobre la democracia}

Las concepciones recogidas acerca de la democracia mostraron tres posturas: un primer grupo que concibe la democracia principalmente como una forma de vida, un segundo grupo que la describe únicamente como un sistema de gobierno y un tercero que menciona ambas características.

Los docentes que conciben la democracia como forma de vida mencionan que vivir en democracia significa libertad de elegir la propia opción de vida, una forma de convivencia en tolerancia, de ideas, opiniones, de respeto, solidaridad y apoyo mutuo (P2, P4).

P2: Es la oportunidad de vivir libremente y en todo estamento de la vida. En la escuela, en el trabajo, en la universidad, en mi casa, en el medio de transporte. Es vivir libremente, en armonía y en paz [...]; vamos a ser un país [democrático] en la medida que también cada uno de los integrantes del país $[\ldots]$ realmente reconozcamos cómo es vivir en democracia, con respeto, con valores, con solidaridad, en armonía, en apoyo mutuo, en aspiraciones a través del esfuerzo de cada uno de nosotros.

Por su parte, los docentes que identificaron la democracia como una forma de gobierno consideran que es la posibilidad de elegir a los representantes (P1, P3, P6, P8), como lo muestran las siguientes viñetas:

P8: [...] Democracia es elegir tu gobierno, [...] no es el que hable mejor, ni el que ofrezca, sino tú tienes que saber, tienes que saber, tienes que, ¿cómo te diré? Tener criterio y el criterio te lo da la educación, te lo da el saber, te lo da la experiencia, lo que ves. Entonces, democracia es elegir a los que te van a gobernar, pero solo con criterio. Hacerlo con deber, con criterio.

E: Muy bien. ¿Cree que el Perú es un país democrático?

P3: Claro. Sí, porque las autoridades siempre se eligen democráticamente. 
E: ¿Y ya eso es suficiente para que sea democrático?

P3: Claro.

Es importante mencionar que dos docentes integraron ciertas características de la democracia como forma de vida con rasgos de la democracia como estilo de gobierno (P1 y P7). Por ejemplo, en la siguiente viñeta, se define democracia como «gobernar para las grandes mayorías», aludiendo a su concepción como sistema de gobierno, y -al mismo tiempo- se incluye el «practicar deberes y exigir derechos», entendiendo democracia también como una forma de vida del ciudadano: P7: «Para mí, democracia acá en la población, es practicar deberes y también exigir derechos a nivel político, gobernar para las grandes mayorías, ¿no? Escuchar a las grandes mayorías. Esas dos cosas».

Los docentes identificaron ventajas de la democracia, tales como la libertad para escoger una opción de vida, el gozar de libertad de expresión, y el vivir en armonía y con capacidad de resolver positivamente los conflictos. Un docente consideró que la democracia es ventajosa frente al autoritarismo, puesto que permite contar con mecanismos que ayudan a contrarrestar la corrupción y la concentración del poder (P7). Ahora, si bien todos los docentes encontraron beneficios en la democracia, al preguntarse expresamente por su importancia, dos docentes no se mostraron convencidos de ella (P2 y P8). Uno de ellos afirmó que optaría por un gobierno de mano dura antes que por un gobierno democrático (P8); y el otro, que preferiría un gobierno democrático que «sepa aplicar normas». Es importante indicar que esta combinación entre un gobierno democrático y un gobierno de mano dura, también se presentó en dos de los docentes que reconocieron la importancia de la democracia (P4 y P6).

Con respecto a las creencias acerca de la democracia, algunos profesores piensan que es el «mal menor» o el sistema «menos malo», y que es «muy imperfecto», aunque el más perfecto con que contamos (P6, P7 y P8). Asimismo, algunos sostuvieron que la democracia es blanda, no aplica normas y no exige que estas se cumplan (P2 y P4), que puede conducir a excesos y libertinaje (P6, P1, P2, P7), y que funciona para la conveniencia de algunos grupos de poder que defienden sus propios intereses y no los del pueblo (P2, P5, P7). Por ejemplo:

P6: [La democracia] Es la menos mala de los sistemas que existen en el mundo [...] Porque las otros sistemas son malas [risas]; te hablo del comunismo, del socialismo, de todos los otros sistemas que no se me vienen ahorita. La democracia te da libertad de cierta manera, también sabiendo cómo lo utilizan los gobernantes, ¿no?

P1: Tenemos todo el entorno político o el entorno jurídico que tenemos es democrático, porque nada está puesto a rajatabla. El problema es que 
la gente confunde la democracia con el libertinaje. [...] no es democrático, por ejemplo, que nosotros tengamos todos esos programas en la televisión totalmente absurdos, fuera de cultura; no es democrático, porque entonces no nos permite a los que estamos mirando esto elegir. No podemos elegir, porque todos los canales están plagados de esos programas absurdos. [...] Ahí eso es libertinaje total; por ejemplo, ya no es democracia.

P2: Porque la democracia, porque la democracia solo está, eh, centrada en los intereses de unos cuantos. No hay la democracia, porque lo que es democracia para uno, para otros es no democracia; es lo opuesto. Entonces, desde ese punto de vista, el país no puede ser democrático, porque todos no tienen la misma oportunidad de expresarse o de reclamar un derecho que le corresponde, ¿no?

Muchos docentes complementaron sus ideas con sus propias experiencias. Opinaron, por ejemplo, que la Ley de Reforma Magisterial No. 29944 (Congreso de la República del Perú, 2012) es una injusticia que no ha tomado en cuenta la voz de los docentes mediante una consulta (P5), o que el Estado exige acciones de sus ciudadanos pero no brinda las posibilidades de que se cumplan. En ese marco, resaltaron la poca oferta de capacitación para profesores frente a las exigencias del Ministerio de Educación para el desarrollo docente (P6).

Como vemos, aquellos docentes que comprenden la democracia como un modo de vida sostienen ideas como su vinculación con el bienestar de los ciudadanos (Nussbaum, 2008) y con el ideal de fraternidad en la convivencia (Bobbio, 2001). Sin embargo, no se mencionan elementos constitutivos de la democracia, como su vinculación con el respeto a los derechos humanos, la inclusión de minorías, el reconocimiento del otro o la legitimidad del consenso, por ejemplo. Tampoco, se incluyen cualidades y virtudes de sus ciudadanos, las que permitirían un modo de vida comprometido y articulado alrededor de la cooperación y deliberación (Gamio, 2007). Los conocimientos acerca de la democracia en su cualidad de forma de vida parecen, en este sentido, muy intuitivos y generales. Poseer una concepción integradora de la democracia permitiría al docente articular este conocimiento a su accionar cotidiano en el colegio, con el objetivo de considerarlo como un eje democratizador de la sociedad (Dewey, 2004; Freire, 2010; Apple y Beane, 2005, Giroux, 2008). Como se ha visto, muchas de las creencias de estos profesores no favorecerían el apoyo a la democracia por considerarla fallida o «blanda» y susceptible de llevar a lo que ellos consideran «libertinaje». Es importante señalar que los profesores no mostraron mayor conciencia sobre la contradicción entre decir que la democracia es importante $y$, a la vez, señalar que prefieren un gobierno que combine la democracia con mano dura. 


\section{Concepciones y creencias sobre la democracia en el colegio}

Acerca de las concepciones sobre la democracia en el colegio, siete docentes (P1, P2, P3, P4, P5, P6 y P7) plantearon que la democracia significa participación en programas escolares e iniciativas que tienen que ver con la elección de los representantes del Municipio Escolar (alcaldes por salón y alcalde de la institución) y con programas acerca de democracia que anteriormente se han llevado a cabo en la institución (por ejemplo, el programa «Libertad en Democracia» e iniciativas de Promudeh y el JNE). Por ejemplo, declaran:

E: Muy bien. Hasta aquí, hemos conversado sobre la democracia en un sentido más amplio y resulta que algunas personas creen que el colegio es un espacio en el que se puede construir la democracia. ¿Cree usted que se puede construir democracia desde el colegio?

P3: Ya se ha cumplido. En el colegio ya se ha cumplido.

E: ¿En el colegio se cumple?

P3: Ya ha habido elección de alcalde, teniente alcalde en cada aula.

E: Muy bien. ¿Cree usted que existe una relación entre el trabajo que se realiza en el colegio y la democracia en el país?

P7: Hay intentos de ciertos programas que ha venido de parte del Estado y también de ONGs. Acá, por ejemplo, trabajó una ONG que se llamaba «Deliberando en democracia», se llamaba el proyecto, que era financiado por EE.UU. Después, me parece que Promudeh, también, tiene algunos programas acá en la escuela; después, el JNE a través de las elecciones de los alcaldes, regidores. Acá, en el colegio, de repente eso.

Adicionalmente, cuatro de los entrevistados describen la democracia desde concepciones que se centran en el docente (P1, P2, P3 y P4), afirmando que «democracia en el colegio» significa cumplir las leyes escolares y las exigencias del Ministerio de Educación (por ejemplo, llevar capacitaciones); trabajar en un ambiente de paz, tranquilidad y respeto entre profesores; desarrollar juntos el «eje curricular» o la programación anual al inicio de año, y elegir a los representantes de sus comisiones docentes (por ejemplo, la comisión de disciplina). En relación con ello, dos docentes señalan:

P2: Donde todos los maestros podamos vivir en un ambiente de armonía, de coordinación permanente, de intercambio de conocimientos permanentement que va a redundar en nuestros alumnos, porque ellos van a ver la sapiencia de sus profesores; los chicos van a ver la preocupación de sus profesores permanentemente, van a ver la 
coordinación de sus maestros, y el chico simple y llanamente, ¿no? Si lo ponemos dentro de un hogar, en el hogar él ve comunicación; amor entre padre, madre, hijos; preocupación de papá, mamá, por ellos mismos; y en su colegio, ellos van a encontrar eso. Entonces, el chico está garantizado, ¿no?, en la convivencia democrática.

P1: Al principio, los maestros nos reunimos antes de que vengan los chicos aquí, al colegio, y hacemos como una especie de FODA o un diagnóstico, y decimos cuáles han sido los problemas que hemos tenido. Entonces, sobre esa problemática, armamos un eje transversal. Es decir, ese eje transversal nos va a servir para que, a partir de ese momento, nosotros hagamos todas nuestras sesiones de clase, nuestras unidades didácticas, $\mathrm{y}$ vayamos orientados a tratar de suplir esas necesidades que tienen los chicos de todas las áreas -matemática, lenguaje, historia, religión- y todos vamos apuntalando a ese tema. Entonces, ahí está la democracia, porque todos opinan $[\ldots]$.

Por otro lado, un docente mencionó que la democracia en el colegio es que el estudiante escuche, atienda y respete al docente: «Con las acciones. Con las acciones. Cada día hablando, hablando a los muchachos; así, se cultiva la democracia. No sé quién perderá tiempo. Un minuto es; lo democrático es esto: escucha el alumno, atiende, respeta. Eso es» (P3).

Como puede verse, estas concepciones no incluyen elementos ciudadanos, como la deliberación y el debate de ideas. De este modo, para los profesores se reduce la participación democrática a las elecciones o al cumplimiento de normas, y se deja de lado concepciones que se relacionan con cultura democrática y otros tipos de participación. Sin duda, este modo de pensar podría generar que los docentes no establezcan acciones dirigidas a brindar un espacio institucional democrático, que facilite roles activos de los estudiantes.

Las concepciones de los docentes sobre la democracia en el colegio, que refieren a una convivencia armónica entre ellos mismos y el trabajo conjunto, se expresan como sus propios anhelos, diferentes a la realidad que describen. Esto concuerda con los hallazgos de Flanagan y colaboradores (2010), quienes encuentran en su estudio que la noción de ciudadanía para los profesores se construye a partir de sueños y expectativas. Sin embargo, llama la atención la poca articulación entre los deseos de los docentes sobre el clima de la institución en relación con la convivencia con sus colegas, por un lado, y la formación de estudiantes, por el otro. Por ejemplo, el asumir que los estudiantes se desarrollarán democráticamente mientras vean que sus profesores «viven en un ambiente armonía, de coordinación permanente, de intercambio de conocimientos permanentemente» (P4) sugiere que, para que el colegio sea democrático, es suficiente que los estudiantes observen las acciones entre docentes y su convivencia en armonía. En esta lógica, el estudiante no toma rol alguno en la construcción de democracia. 
Asimismo, es importante mencionar que muchos docentes consideraron a la familia como un impedimento para la formación de los estudiantes y para la labor del colegio (P1, P3, P5, P7), lo que es consistente con los resultados de otros estudios (Flanagan et ál., 2010; Apaza, 2009). Estas concepciones limitan las posibilidades de que la familia participe de la construcción de democracia en el colegio, pues parece poco integrada a la labor del docente. A pesar de que las familias no siempre están motivadas para apoyar mejores aprendizajes en sus hijos, ni disponen del tiempo ni espacio físico para generar acciones concretas que permitan materializarlos, se ha probado que el involucramiento de estas es beneficioso para el buen desempeño del estudiante (Fantuzzo et ál., 2004). Los profesores que sostuvieron concepciones negativas sobre la familia argumentaron que el colegio puede hacer muy poco o nada por los estudiantes con problemas familiares (P2, P3, P5, P7 y P8).

Es interesante señalar que algunos docentes mostraron concepciones de sí mismos y su rol como profesores que pueden entrar en conflicto con el de facilitador de aprendizajes y gestor de procesos democráticos. Por ejemplo, algunos señalan que el profesor debe ser una figura de autoridad para el estudiante, a veces, una figura paternal o maternal, y que, además, debe «ser amigo, tiene que ser un poco de padre, de hermano mayor» (P4). Un ejemplo de esto es el siguiente:

E: ¿Qué problemas pueden surgir si se involucra a los estudiantes en la toma de decisiones del colegio?

P4: Bueno, problemas de que los alumnos pueden faltar el respeto al profesor... y ya, pues, deja de ser autoridad el profesor. Y el profesor es autoridad y paradigma, a la vez, del alumno.

P9: [...] la situación de que los respetos no se dan: el profesor entra a una sala ¡sí, cállese la boca, gua, gua, gua! Al profesor se lo respeta por lo que es; él tiene que entrar y todos tienen que darse cuenta que entró el profesor.

Algunos docentes sostuvieron creencias que favorecen la violencia de los profesores hacia los estudiantes, manteniendo que muchos estudiantes constituyen una amenaza a su integridad o justificando la violencia física o los gritos cuando estos se aplican de forma «justa». Por ejemplo:

P2: [...] ya ves que yo discrepo también mucho con esos alcances del Ministerio de Educación que «al niño ni con el pétalo de una rosa». Oye, mi hijo se porta mal, te vas a tu cuarto no te quiero ver, pero mi hijo ya se porta de una manera que es grosera, es brutal; yo sí soy capaz de jalarle una oreja, porque ya tú le hablas con amor, «hijito, por favor, hijito»; esa labor es horrorosa. ¿Dónde queda el derecho de ese alumno? ¿Y el 
de derecho de los demás alumnos? ¿El derecho de los demás alumnos de trabajar en paz?

P4: Hoy en día, el niño, la mujer somos bien avalados; estamos protegidos por nuestros derechos. No podemos enmancillar a un niño y a una mujer, más que todo un niño; un profesor tiene que respetar a un niño. Si alzamos la voz, tenemos que alzar pero este, con una manera eh democrática, soberbia y justa, con lo que hacemos; ya no estamos en ese tiempo de que «chico, tú no atiendes la clase, entonces, te vas, te largas, ya vete al patio»; no, así, ya no ya. Ya no.

Es posible pensar que aquellos que comprenden el rol del profesor como una figura de autoridad no promoverían relaciones horizontales y democráticas con los estudiantes y, eventualmente, con los demás agentes educativos. En ausencia de regulaciones, los profesores puedan ejercen violencia sobre sus estudiantes, debido a que no parecen comprender el sentido de no agredir a los estudiantes ni tampoco ofrecen medidas correctivas alternativas que sean efectivas para el cambio de la conducta. Un ejercicio autoritario y rígido del rol docente puede, además, favorecer situaciones de violencia en los colegios, pues se sabe que, a mayor grado de autoritarismo, mayores manifestaciones de violencia escolar (Kornblit, Adaszko y Di-Leo, 2012). La contraparte de esta visión autoritaria está conformada por las concepciones del rol docente como figura paternal o amigo, las que se construyen a partir de las carencias que los profesores encuentran en las familias y de una mirada paternalista sobre los estudiantes que los ubica en una relación vertical. Estas creencias no favorecerían climas escolares que propicien el diálogo auténtico, que abran canales de comunicación y que valoren a los estudiantes como legítimos participantes de la vida escolar, lo que podría disminuir considerablemente la frecuencia de situaciones violentas (Adaszko y Kornblit, 2008 en Kornblit et ál., 2012).

Con respecto a la participación estudiantil en la vida escolar, si bien la mayoría de docentes piensa que los estudiantes deben participar en el desarrollo de normas escolares, puesto que esto los compromete de mejor manera a cumplir con dichas normas, también sostiene que la participación debe estar siempre dirigida por un docente. Asimismo, añaden que debe ponérsele límites para evitar que las reglas acordadas sean muy «utópicas» e imposibles de cumplir. Algunos profesores consideraron que la participación de los estudiantes debe restringirse a expresar sus opiniones sobre las propuestas de normas que presentan los docentes a fin de que «no se caiga en el libertinaje que los chicos quieren» (P2, P5). Por su parte, un profesor se mostró abiertamente en contra de la participación de los estudiantes. En relación con ello, estas son algunas de sus opiniones:

P2: [...] el chico, en su aporte, va a querer libertinaje; [...] yo le debo explicar al chico y lo puedo entrar en juicio y conocimiento. [...] 
Entonces, la problemática puede ser que ellos puedan poner lo que quieran de acuerdo con sus interés, pero ya los maestros, los directivos, tenemos que razonar; y yo sé que este chico va a entrar en razón; el estudiante lo va a entender y lo vamos a convencer y va a razonar: «ah sí, profesora, tiene razón; sí, director, tiene razón». Ese es el sentido [...].

P5: [...] ellos pueden decir muchas cosas, pero no se les puede dar tampoco mucha libertad, [...] porque sino ellos harían del colegio lo que ellos quisieran, porque, por ejemplo, siempre hay normas que hay que cumplir, ¿no?; y ellos, por ejemplo, saben de que tienen que venir con el uniforme y, bueno, de repente allí tú les dices que ellos pueden hacer lo que quieren, ya no vienen con el uniforme; vienen como sea, no tienen presencia, entonces.

P8: [...] el problema puede surgir si es que «jJóvenes tomen, este, hagan su reglamento, ¿ya? Yo ahorita vengo; me estoy yendo un rato a la calle!». Ahí sí, caos. Pero, si se quedan profesores y es ¡dirigido!, ninguno. Siempre, esto viene de la casa; siempre, hay alumnos que van a decir sonseras y van a hacer las cosas mal; siempre, hay chicos que no tienen reglas; siempre, hay chicos que van a hacer lo que quieran; siempre, hay chicos matones; siempre, hay «Pepe el vivo», como digo, que -según éltodo se hace como yo quiero y si no te pego, porque es lo que ve en su casa. O sea, allí está el profesor para guiar eso.

P4: [...] ya sabemos a qué punto vamos a ir, cuál es nuestra meta. Para eso, somos profesionales; no somos cualquier cosa. ¿Cómo vamos a hacer intervenir a los alumnos si nosotros ya sabemos el derecho del niño y el adolescente? Siguiendo estos puntos, nosotros podemos hacer un buen reglamento.

La participación de los alumnos es un elemento fundamental en la creación de instituciones democráticas (Power, Higgins y Kohlberg 1989; Apple y Beane, 1995), pues la elaboración de políticas y reglas que reflejan normas compartidas y valores de la comunidad es una manera de promover actitudes democráticas en los estudiantes. Pese a ello, como se observa, a pesar de declarar que se reconoce la importancia de la democracia, muchos docentes no están valorando la participación como una oportunidad para el desarrollo de competencias de deliberación y reflexión en sus estudiantes. A esto se suma que algunos docentes se mostraron abiertamente en desacuerdo con la participación de los estudiantes en la creación de normas, y se ubican por encima de ellos y desvalorizan sus aportes. Lo interesante es que, a la par de estas concepciones negativas, también, se recogieron creencias que pueden facilitar la participación de los estudiantes en la creación de reglas. De esta manera, se evidencia que coexisten en los profesores concepciones contradictorias. 
Finalmente, siendo autocríticos, algunos profesores reconocieron ser poco democráticos en sus acciones, lo que puede ser una oportunidad para la construcción de la democracia en el colegio, en la medida que una postura crítica sobre su rol como docentes les permite cuestionar sus creencias, y generar nuevos conocimientos y cambios específicos con respecto a ellas (Alberca y Frisancho, 2011).

P1: Haciéndome una autoevaluación, tampoco, soy tan democrática que digamos; por ejemplo, los chicos, tal vez yo les deje un trabajo, yo les estimo, les doy un sistema, y quiero que sea así, y cuando alguno me quiere cambiar de modo entonces trato, me es incómodo. Claro que le digo que sí lo acepto, pero me es incómodo. Entonces, desde ese punto de vista, un ejemplo así pequeñito, ya no hay democracia, ¿no? O, cuando mis hijas quieren optar por otra profesión y yo trato de que ella vaya por otro lado, entonces, tampoco lo estoy siendo.

P6: Porque es verdad, nosotros en muchos docentes que no estamos adecuadamente preparados, no manejamos adecuadamente información, ¿no? Nos resistimos a ciertos cambios propios de la naturaleza, propios del desarrollo de una país, propios del mundo que nos arrastra, y estamos quedados en el tiempo; y eso también es un factor para, para podernos desarrollar a nuestros alumnos democráticamente.

\section{Conclusiones}

El presente estudio tuvo por objetivo explorar las concepciones y creencias acerca de la democracia en el colegio en profesores de secundaria de una institución pública de Lima, bajo el supuesto de que la estructura de creencias de los docentes se involucra y juega un papel relevante en la enseñanza y la práctica pedagógica en general. A partir de los resultados, se concluye que los docentes de esta institución no reconocen la construcción de una sociedad democrática como fin de la educación, sino que perciben que su objetivo principal es formar emprendedores y personas preparadas para el mundo laboral, o brindar contenidos del área curricular de su especialidad. Si bien mencionan el desarrollo de habilidades y la formación integral como fines de la educación, estos no aparecen explícitamente articulados con el desarrollo de la ciudadanía de sus estudiantes.

Las concepciones de la democracia como un sistema de gobierno imperfecto y cuestionable, muy frecuentes entre los docentes participantes, podrían significar una barrera hacia la construcción de la democracia como un modo de vida en el colegio. Es necesario, por ello, que los profesores tengan más y mejor información sobre la democracia y sus procesos, puesto que esto ayudará a que su criterio para juzgar aspectos relacionados con la democracia sea 
más complejo y fundamentado. Asimismo, les dará mayores elementos para promoverla y reconocerla al interior de la institución educativa. Además de proporcionar información sobre democracia, para garantizar el apoyo al sistema democrático y su legitimidad percibida, se requiere trabajar sobre las creencias de estos docentes, pues ellos -como agentes de cambio-son aliados fundamentales para la construcción de una cultura democrática en el colegio.

En el colegio, la democracia se entiende, principalmente, como participación en programas escolares, lo que limita su comprensión como cultura escolar, en la medida que la restringe solo a actividades específicas y procedimentales, como la elección de representantes estudiantiles. También, se piensa que la democracia en el colegio se asocia a acciones centradas en el docente, que parecen estar relacionadas a anhelos de los profesores, sin especificidad de cómo lograr que la democracia incluya a los estudiantes. Asimismo, se comprueba que los docentes perciben a las familias y a los propios alumnos como barreras para su trabajo, lo que no les permitiría considerarlos plenamente como agentes activos del proceso democrático. Además, creen que es poco lo que se puede hacer desde la institución por sus estudiantes, aspecto que podría indicar la sobrecarga de trabajo a la que los profesores están expuestos en su práctica cotidiana.

Las creencias sobre su rol como docentes, junto con aquellas sobre la disciplina y los métodos correctivos, parecen alejar a los profesores de posturas democráticas. Preocupan, especialmente, las relaciones verticales que podrían estarse estableciendo con los estudiantes y la justificación del uso de la violencia en el colegio por falta de conocimiento de otros mecanismos de disciplina efectivos. La construcción de la democracia es impensable en una institución que sostenga la violencia como método disciplinario, debido a que esta restringe toda posibilidad de cooperación, participación y deliberación de los alumnos, y los trata como medios, no como fines. Contrariamente, las concepciones que sostiene la participación de los estudiantes en la elaboración de normas de la institución brindan una oportunidad para la construcción de un colegio más democrático.

Finalmente, cabe resaltar que no se encontró ninguna relación entre las concepciones y creencias encontradas a lo largo del presente estudio y aspectos como el tiempo de servicio de los profesores, el sexo, la especialidad de formación, ni el área curricular a cargo.

Para profundizar en los hallazgos en estudios similares al presente, se recomienda complementar las entrevistas cualitativas con observaciones de la práctica pedagógica de los docentes, así como, también, indagar más profundamente en las experiencias que podrían influenciar sus concepciones, sus creencias y su práctica. De esta manera, podría establecerse más claramente la relación entre la estructura de creencias y el actuar docente, lo que sería un insumo muy importante para el diseño de intervenciones adecuadas para el cambio conceptual y pedagógico del profesor. Por último, se sugiere la implementación y evaluación de espacios de reflexión para poder contrastar la manera en que la práctica pedagógica se transforma a través de los mismos. 


\section{Notas biográficas}

LuCía Ginocchio es licenciada en Psicología con mención en Psicología Educacional y egresada de la Facultad de Artes Escénicas (Fares) de la especialidad de Danza. Actualmente, trabaja en el Instituto de Estudios Peruanos (IEP) como asistente de investigación en el área de Educación. Sus temas de interés en psicología de la educación son la formación ciudadana, el desarrollo moral y la educación intercultural. Asimismo, es miembro del Grupo de Investigación Educación y Ciudadanía Intercultural del Departamento de Psicología de la Pontificia Universidad Católica del Perú.

Susana Frisancho es doctora en Psicología del Desarrollo por la Universidad de Fordham, New York. Asimismo, es magíster en Psicología y Psicóloga Educacional por la Pontificia Universidad Católica del Perú, donde se desempeña como profesora principal del Departamento de Psicología y es coordinadora del Grupo de Investigación en Cognición, Aprendizaje y Desarrollo (G-CAD). Es especialista en desarrollo cognitivo y desarrollo moral, constructivismo y construcción del conocimiento, educación moral, educación ciudadana, educación y cultura, epistemología del profesor y procesos de formación y reflexión docente.

María Isabel La Rosa es profesora asociada del Departamento de Psicología de la Pontificia Universidad Católica del Perú (PUCP) y presidente del Comité de Ética para la investigación con seres humanos y animales de la PUCP. Es licenciada en Psicología Educacional por la Universidad Peruana Cayetano Heredia (UPCH) y magíster en Psicología Evolutiva y de la Educación por la Universidad Autónoma de Barcelona (UAB). También, es miembro del Grupo de Investigación en Cognición, Aprendizaje y Desarrollo (G-CAD).

\section{Referencias}

Alberca, R. V. y Frisancho, S. (2011). Percepción de la reflexión docente en un grupo de maestros de una escuela pública de Ayacucho. Educación, 20 (38), 25-44.

Ames, P. (1999). El poder en el aula: Un estudio en escuelas rurales andinas. En M. Tanaka (Comp.), El poder visto desde abajo. Lima: Instituto de Estudios Peruanos.

Apaza, C. (2009). Retos y posibilidades de la educación para la democracia. Un análisis desde la perspectiva de los docentes. En F Reátegui, F. (Coord.), Formación en ciudadanía en la escuela peruana: Avances conceptuales e investigaciones. Lima: Idehpucp. 
Apple, M. W. y Beane, J. A. (1995). Democratic schools. Virginia: Association for Supervision and Curriculum.

Becerra, S. (2011). Valores de equidad y aceptación en la convivencia de escuelas en contexto indígena: La situación del prejuicio étnico docente hacia los estudiantes Mapuche en Chile. Revista de educación, número extraordinario, 163-181.

Benavides, M. (1997). Grandes unidades escolares y violencia: Un modelo para desarmar. En F. T. Tellez (Ed.), Análisis de políticas: Documentos sobre problemas educacionales en América Latina (267-334). Santiago: Reduc.

Bobbio, N. (2001). El futuro de la democracia. México D.F: Fondo de Cultura Económica.

Borg, M. (2001). Teachers' Beliefs. ELT Journal, 55(2), 186-188.

Callirgos, J. C. (1995). La discriminación en la socialización escolar. Lima: Pontificia Universidad Católica de Perú.

Carrión, J., Zárate, P. y Seligson, M. (2012). Cultura política de la democracia en Perú, 2012: Hacia la igualdad de oportunidades. Lima: Instituto de Estudios Peruanos.

Catalán, J. (2011). Del pensamiento al conocimiento profesional del profesor. En J. Catalán (Ed.), Psicología educacional. Proponiendo rumbos, problemáticas y aportaciones. La Serena: Editorial Universidad La Serena.

Congreso de la República del Perú (2003). Ley General de educación No. 28044. Recuperado de http://www.minedu.gob.pe/p/ley_general_de_ educacion_28044.pdf

(2012).LeydeReformaMagisterialNo.29944. Recuperado de http://www.minedu.gob.pe/files/4966_201212101158.pdf

Dewey, J. (2004). Democracia y educación: Una introducción a la filosofía de la educación. Madrid: Morata.

Dibós, A., Frisancho, S. y Rojo, Y. (2004). Propuesta de evaluación de formación ciudadana. Lima: Ministerio de Educación del Perú.

Durkheim, E. (1976). Educación como socialización. Salamanca: Sígueme.

Espinoza, G. (1993). Los que mandan y los que obedecen. Planteamientos sobre el papel de la autoridad y la disciplina escolar dentro de una educación en derechos humanos. Lima: Ipedehp.

Evans, E. (2004). ¿La escuela educa para la democracia o para el autoritarismo?. En J. Ansión y A. Villacorta (Eds.), Para comprender la escuela pública: Desde sus crisis y posibilidades. Lima: Fondo Editorial de la Pontificia Universidad Católica de Perú.

Fantuzzo, J., McWayne, C., Perry, M. y Childs, S. (2004). Multiple Dimensions of Family Involvement and their Relations to Behavioral and Learning Competencies for Urban, Low-Income Children. School Psychology Review, 33, 467-480. 
Flanagan, A., Cerda, G., Lagos, D. y Riquelme, S. (2010). Tensiones y distensiones en torno a la ciudadanía y formación ciudadana: Comparación de los significados de profesores y estudiantes secundarios en la región de Valparaíso. Última Década, 33, 115-137.

Freire, P. (2010). La educación como práctica de la libertad. Buenos Aires: Siglo Veintiuno Editores.

Gamio, G. (2007). Explorando la democracia. Recuperado de http:// gonzalogamio.blogspot.com/search?q=democracia+y+ciudadania

Giroux, H. A. (2008). Introducción: Democracia, educación y política en la pedagogía crítica. En P. McLaren y J. L. Kincheloe (Eds.), Pedagogía crítica. De qué hablamos, dónde estamos. Barcelona: Graó.

Glaeser, E. L., Ponzetto, G. y Shleifer, A. (2006). Why Does Democracy Need Education? (Working Paper 12128). National Bureau of Economic Research Working Paper Series. Recuperado de http://www.nber.org/ papers/w12128

Guerra, F. (2014). Creencias sobre ciudadanía y educación ciudadana en docentes de un colegio público y un colegio privado de Lima (Tesis de Licenciatura en Psicología). Pontificia Universidad Católica del Perú, Lima. Recuperado de http://tesis.pucp.edu.pe/repositorio/handle/123456789/5081

Hernández, R., Fernández-Collado, C. y Baptista, L. (2010). Metodología de la investigación. México: McGraw Hill.

Kornbilt, A., Adasko, D. y Di Leo, F. (2012). Clima social escolar y violencia: un vínculo explicativo posible. Un estudio de escuelas medias argentinas. En C. Berger y C. Lisboa (Eds.), Violencia escolar. Estudios y posibilidades de intervención en Latinoamérica. Santiago de Chile: Editorial Universitaria.

Kymlicka, W. y Norman, W. (2002). El retorno del ciudadano: Una revisión de la producción reciente en teoría de la ciudadanía. Ágora, 7, 5-42. Recuperado de: http://www.cholonautas.edu.pe/modulo/upload/kymlick. pdf

Leal, F. (2005). Efecto de la formación docente inicial en las creencias epistemológicas. Revista Iberoamericana de Educación, 34(5), 1-16.

Marshall, T. H. (1992). Citizenship and social class. Londres: Pluto Press.

Ministerio de Educación del Perú (2005). Evaluación Nacional del Rendimiento Estudiantil 2004. Una primera aproximación a la evaluación de la reflexión ciudadana. Lima: Unidad de Medición de la Calidad Educativa, Ministerio de Educación del Perú.

Nussbaum, M. (2008). Toward a globally sensitive patriotism. Daedalus, 137(3), 78-93. Recuperado de: http://www.mitpressjournals.org/doi/abs/10.1162/ daed.2008.137.3.78?journalCode $=$ daed

Nussbaum, M. (2010). Not for profit: Why democracy needs the humanities. New Jersey: Princeton University Press. 
Oliart, P. (1996). ¿Amigos de los niños? Cultura académica en la formación del docente de primaria. Lima: Grade.

Oser, F., Althof, W. y Higgins-D’Alessandro, A. (2008). The just community approach to moral education: System change or individual change? Journal of Moral Education, 37(3), 395-415.

Pajares, F. (1992). Teachers' beliefs and educational research: Cleaning up a messy construct. Review of Educational Research, 62(3), 307-332.

Ponte, J. (1999). Las creencias y concepciones de maestros como un tema fundamental en formación de maestros. En K. Krainer y F. Gorffree (Eds.), On research in teacher education: From a study of teaching practices to issues in teacher education (43-50). Osnabrück: Forschungsintitut für Mathematikdidaktik. Traducción (resumida) de Casimira López. Recuperado de: http://www.educ.fc.ul.pt/docentes/jponte/docs-sp/ Las\%20creencias.doc el 20/04/08

Power, F. C., Higgins, A. y Kohlberg, L. (1989) Lawrence's Kohlberg approach to moral education. New York: Columbia University Press.

Rojas, V. (2011). «Prefiero que me peguen con palo... las notas son sagradas». Percepciones sobre disciplina y autoridad en una escuela pública en el Perú. Lima: Grade.

Tallone, A. (2010). El desafío de la convivencia escolar. En B. Toro y A. Tallone (Coord.), Educación, valores y ciudadanía. Madrid: Organización de Estados Iberoamericanos para la Educación, la Ciencia y la Cultura.

Trinidad, R. (1999). Prácticas y percepciones en torno a la imposición de la disciplina y las manifestaciones de resistencia de los alumnos en un colegio estatal de Lima (Tesis de Licenciatura en Antropología). Pontifica Universidad Católica del Perú, Lima.

Touraine, A. (1995). ¿Qué es la democracia? Montevideo: Fondo de Cultura Económica. Recuperado de: http://www.cholonautas.edu.pe/modulo/ upload/Touraine\%20cap1.pdf

Tubino, F. (2009). La formación de la razón pública en las democracias multiculturales. Razón práctica y asuntos públicos. Revista de Ética y Filosofía Política, 10. Recuperado de http://intercambiofilosofico.blogspot. com/2009/03/revista-razon-practica-y-asuntos.html

Veramendi, M. L. (2012). Educación y ciudadanía: Análisis de la relación entre trayectoria educativa, literacidad, êthos y praxis política en una muestra de adultos de un distrito de los Andes peruanos. Lima: Grade.

Wertsch, J.V. (2007). Mediation. En H. Daniels, M. Cole y J. V. Wertsch (Eds.), The Cambridge Companion to Vygotsky. New York: Cambridge University Press.

Zeballos, A. (2012). La escuela: Aprendiendo a leer, sumar y obedecer. Revista Isees, 10, 61-75. 